\title{
Analysis of Factors Affecting Economic Growth in Bangka Belitung Province, Indonesia With LSDV and FGLS Methods
}

\author{
Darman Saputra \\ Departement of Management, Faculty of Economics, University of Bangka Belitung \\ saputradarman1988@gmail.com
}

\begin{abstract}
The Least Square Dummy Variable (LSDV) method can be used to estimate parameters in the panel data regression model incomplete one-way fixed effect. To produce the best model with GDP data of GRASB. Variables that do not occur heteroscedasticity and models that meet the smallest sum square of error is the variable Mining and Processing Industry, this variable affects the per capita income. The Feasible Generalized Least Square (FGLS) method can be used to estimate the regression parameters for incomplete panel data for a one-way random effect. In this model produce the best model with non-oil and gas GRDP data. The variables that fulfill it are the processing Industry, service and agriculture of Forestry and Fishery. Therefore looking at the above model can be concluded non-oil and Gas GRDP has three factors that affect per capita income in Bangka Belitung. This should be a reference of local governments to further improve the quality or production in agriculture and services because this potential is more promising for the future. Software used to analyze data in this paper is with $R$.
\end{abstract}

Keywords: Heteroscedasticity, Panel data is not complete, Least Square Dummy Variable (lSDV), Feasible Generalized Least Square (FGLS), R.

\section{Pendahuluan}

Pembangunan daerah harus sesuai dengan kondisi potensi serta aspirasi masyarakat yang tumbuh dan berkembang. Apabila pelaksanaan prioritas pembangunan daerah kurang sesuai dengan potensi yang dimiliki oleh masing-masing daerah, maka pemanfaatan sumber daya yang ada menjadi kurang optimal. Keadaan tersebut dapat mengakibatkan lambatnya proses pertumbuhan ekonomi daerah yang bersangkutan. (Prishardoyo, 2008). Data panel memiliki banyak kelebihan yang terdiri dari data yang lebih informatif (bervariasi, lebih besar dan efisien), mendalami efek-efek ekonomi yang tidak dapat diperoleh jika hanya menggunakan data time series atau cross section saja (Hsiao, 1986). Data panel disebut tidak lengkap (unbalanced panel data) jika jumlah observasi berbeda untuk unit cross-section atau dengan kata lain ada data atau nilai yang hilang (missing value). Secara singkat : $\left\{x_{i t}, y_{i t}\right\}$ untuk $\mathrm{i}=1,2, . ., \mathrm{N} ; \mathrm{t}=1,2, \ldots, \mathrm{T}$ atau $\mathrm{T}_{1}=\mathrm{T}_{2}=\ldots=\mathrm{T}_{\mathrm{N}}$ sehingga banyaknya keseluruhan observasi data panel adalah $\sum_{i=1}^{N} T_{i}$.

Heteroskedastisitas dalam model panel merupakan suatu keadaan atau fenomena penyimpangan asumsi dimana variansi dari masing-masing komponen $u_{i t}$ adalah suatu konstanta yang bernilai tidak sama atau lebih sering dikenal dengan nama homoskedastisitas. Komponen $u_{i t}$ sendiri memiliki dua komponen yang mempengaruhi model panel tersebut yaitu $u_{i}$ yang merupakan efek khusus individual yang tidak tampak dan komponen galat $v_{i t}$ 
yang merupakan nilai nilai galat dari model panel linear untuk semua observasi unit crosssectional untuk semua periode (Baltagi, 2005). Didalam penulisan ini, permasalahan yang akan dibahas difokuskan pada pembentukan model data panel tidak lengkap (unbalanced panel data): Satu arah (one-way) pada fixed effect menggunakan Least Square Dummy Variable (LSDV) dan pada random effect menggunakan Feasible Generalized Least Square (FGLS).

\section{Kajian Pustaka}

\section{Heteroskedastisitas}

Heteroskedastisitas adalah fenomena penyimpangan asumsi dimana variansi dan masing masing komponen galat $u_{i t}$ (bersyarat terhadap pemilihan prediktor) merupakan suatu konstanta yang bernilai tidak sama. Nama lain untuk heteroskedastisitas adalah variansi galat yang tidak konstan. Dalam konteks model panel linear, diasumsikan sedemikian sehingga variansi dari masing-masing galat $u_{i t}$ (bersyarat terhadap pemilihan prediktor) merupakan suatu konstanta yang bernilai sama. Keadaan ini disebut dengan homoskedastisitas.

\section{Teori Hipotesis}

Pengujian terdapat atau tidaknya data yang bersifat heteroskedastisitas dapat mengunakan uji White. Dalam uji White, diuji hipotesis null $\mathrm{H}_{0}$ : asumsi homoskedastisitas dari komponen error terpenuhi versus $\mathrm{H}_{1}$ : error bersifat heteroskedastisitas.

\section{Model Regresi Data Panel Tidak Lengkap}

Didefinisikan model regresi untuk data panel tidak lengkap yaitu : $y_{i t}=\beta_{0}+\sum_{k=1}^{k} \beta_{k} X_{i t, k}+u_{i t}$ dengan komponen error $u_{i t}$ satu arah didefinisikan : $u_{i t}=\mu_{i}+v_{i t}$ dan komponen error $u_{i t}$ dua arah didefinisikan : $u_{i t}=\mu_{i}+\lambda_{t}+v_{i t}$ dimana $i=1,2, \ldots \mathrm{N} ; t=1,2, \ldots \mathrm{T}_{\mathrm{i}} ; k=1,2, \ldots \mathrm{K}$.

\section{Estimasi Parameter Data Panel Tidak Lengkap}

\section{Fixed Effect Satu Arah dengan Least Squeare Dummy Variable (LSDV)}

Pada model ini mengasumsikan intersep bervariasi antar individu maupun antar waktu, sedangkan slope-nya konstan. Sehingga dapat dibentuk menjadi dua model, yaitu model efek individu dan model efek waktu. Untuk perbedaan intersep-nya digunakan varaiabel dummy.

\section{Model Efek Individu}

Pada model efek individu, intersep diperbolehkan berbeda antar individu, sedangkan slopenya diasumsikan bersifat konstan. Sehingga dalam model ini variabel dummy hanya berperan untuk penggolongan unit individu. $y_{i t}=\beta_{0}+\beta X_{i t}+\alpha_{i}+v_{i t}$ dengan $i=1,2, \ldots, \mathrm{N} ; t=1,2, \ldots \mathrm{T} i$ dan $n=\sum_{i=1}^{N} T_{i}$ atau jika dinyatakan dalam bentuk matriks adalah : $Y=\iota_{n} \beta_{0}+X \beta+M_{\alpha} \alpha+v$.

\section{Model Efek Waktu}

Pada model efek waktu intersep diperbolehkan berbeda antar unit waktu dan slope-nya diasumsikan konstan. Sehingga variabel dummy dalam model ini hanya berperan dalam penggolongan waktu. Model data panel tidak lengkap waktu adalah sebagai berikut : 
$y_{i t}=\beta_{0}+\beta X_{i t}+u_{t}+v_{i t}$ dengan $i=1,2, \ldots, \mathrm{N} ; t=1,2, \ldots, \mathrm{T} i$ dan $n=\sum_{i=1}^{N} T_{i}$ atau jika ditulis dalam bentuk matriks : $Y=\imath_{n} \beta_{0}+X \beta+M_{\mu} \mu+v$.

\section{Random Effect Satu Arah dengan Feasible Generalized Least Square (FGLS)}

Pada model data panel, efek dari level berasal dari individu dan waktu. Oleh karena itu individu dan waktu dipilih secara random, maka efek dari individu dan waktu diasumsikan suatu variabel acak akan dilihat variabilitas masing-masing efek. Dengan demikian, pada model efek random perbedaan karakteristik individu dan waktu terletak pada error dari model. Diasumsikan bahwa komponen error $\mu_{i} \sim \operatorname{IID}\left(0, \sigma_{\mu}^{2}\right)$ dan komponen error $v_{i t} \sim$ IID $\left(0, \sigma_{v}^{2}\right)$. Didefinisikan model regresi untuk data panel tidak lengkap : $y_{i t}=\beta_{0}+\sum_{k=1}^{K} \beta_{k} X_{i t, k}+u_{i t}$ dengan $i=1, \ldots N ; t=1, \ldots T_{\mathrm{i}}$ dan $k=1, \ldots, K$ dimana komponen error $u_{i t}$ dengan : $u_{i t}=\mu_{i}+v_{i t}$ merupakan komponen error satu arah.

\section{Data dan Variabel}

Studi kasus ini menggunakan data yang dikumpulkan dari BPS Provinsi Bangka Belitung yaitu terdiri dari pendapatan per kapita, jumlah penduduk, kemiskinan, PDRB MIGAS (industri pengolahan, pertambangan dan listrik,gas dan air) dan Penduduk sedangkan untuk PDRB NON MIGAS (pertanian, perternakan, kehutanan dan perikanan (PPKP), perdagangan, hotel dan restaurant (PHR), idustri pengolahan dan jasa-jasa) dan Penduduk.

\section{Metode Penelitian}

\section{Effect Model pada Data Panel}

Suatu effect dikatakan fixed effect, jika level dari faktor-faktornya dipilih tertentu berdasarkan keinginan peneliti dari populasi yang ada. Pada model data panel, effect dari level-level antara lain berasal dari individu dan waktu. Oleh karena individu dan waktu yang dipilih tersebut.

\section{Random Effect Model pada Data Panel}

Sedangkan suatu effect disebut random effect, jika level dari faktor-faktornya dipilih secara acak dari populasi level yang ada. Effect dari level-level antara lain dari individu dan waktu. Oleh karena itu individu dan waktu dipilih secara random maka effect dari individu dan waktu diasumsikan suatu variabel acak dan akan dilihat variabilitas masing-masing effect.

\section{Ordinary Least Square (OLS)}

Model linear statistik: $\mathrm{y}=\beta_{1} X_{1}+\beta_{2} X_{2}+\cdots+\beta_{2 k} X_{k}+u$. Dengan sejumlah $\mathrm{n}$ data observasi maka model linear ini dapat ditulis dalam bentuk matriks sebagai berikut:

$$
\begin{aligned}
& \left(\begin{array}{c}
y_{1} \\
y_{2} \\
\vdots \\
y_{t}
\end{array}\right)=\left(\begin{array}{ccc}
x_{11} & \cdots & x_{1 k} \\
\vdots & \ddots & \vdots \\
x_{1 t} & \cdots & x_{t k}
\end{array}\right)\left(\begin{array}{c}
\beta_{1} \\
\beta_{2} \\
\vdots \\
\beta_{t}
\end{array}\right)+\left(\begin{array}{c}
u_{1} \\
u_{2} \\
\vdots \\
u_{t}
\end{array}\right) \\
& \text { Sehingga model ini dapat disederhanakan sebagai } \\
& \mathrm{y}=\mathrm{X} \beta+u
\end{aligned}
$$

\section{Generalized Least Square (GLS)}


Pada penaksiran OLS, asumsi-asumsi yang digunakan dalam model regresi linear $Y=X \beta+u$ adalah $E(\mathrm{u})=0$ dan $\operatorname{Var}(\mathrm{u})=\sum=\sigma^{2} I$. Asumsi variansi error $\sigma^{2} I$ disebut asumsi error spherical, yakni error tidak berkorelasi dan mempunyai variansi yang sama (pada diagonal utama terdapat entri yang sama). Namun tidak tertutup kemungkinan variansi tidak sama atau dengan kata lain terjadi heteroscedastic, sehingga dapat dinyatakan bahwa $\operatorname{Var}(\mathrm{u})=\sum=\sigma^{2} \Omega$.

\section{Hasil dan Pembahasan}

\section{Analisis Data Fixed Effect}

Untuk mengilustrasikan komponen model panel dengan $\mathrm{R}$, model-model panel yang akan diestimasi sebagai berikut:

Model II:

Pendapatan $=b_{1}$ IDP $+b_{2}$ Pertambangan $+b_{3}$ Kemiskinan $+b_{4}$ Penduduk $+c_{i}+d t+\varepsilon_{i, t}$

\section{Analisis Model Fixed Effect}

Tabel 1. Uji Haussman

\begin{tabular}{|l|l|l|l|}
\hline Model 2 & 64.7728 & $2.873 \mathrm{e}-13$ & $\begin{array}{l}\text { Hipotesis } \mathrm{H}_{0} \text { ditolak, } \\
\text { digunakan efek tetap }\end{array}$ \\
\hline
\end{tabular}

Sumber: Data diolah peneliti, 2017

Tabel 2. Uji Breusch-Pagan

\begin{tabular}{|l|l|l|l|l|}
\hline Model 2 & $\mathrm{H}_{0}: \mathrm{c}_{\mathrm{i}}=0, \mathrm{~d}_{\mathrm{t}}=0$ & 62.0638 & $\begin{array}{l}3.334 \mathrm{e}- \\
14\end{array}$ & $\begin{array}{l}\mathrm{H}_{0} \text { ditolak, ada } \\
\text { efek dua arah. }\end{array}$ \\
\cline { 2 - 5 } & $\mathrm{H} 0: \mathrm{c}_{\mathrm{i}}=0$ & 60.5119 & $\begin{array}{l}7.313 \mathrm{e}- \\
15\end{array}$ & $\begin{array}{l}\mathrm{H}_{0} \text { ditolak, ada } \\
\text { efek individu }\end{array}$ \\
\cline { 2 - 5 } & $\mathrm{Ho}: \mathrm{d}_{\mathrm{t}}=0$ & 1.5519 & 0.2129 & $\begin{array}{l}\mathrm{H}_{0} \text { diterima, } \\
\text { tidak ada efek } \\
\text { waktu. }\end{array}$ \\
\hline
\end{tabular}

Sumber: Data diolah peneliti, 2017

Dari hasil uji Hausmann dan Breusch-Pagan di atas, dapat disimpulkan bahwa model-model berikut akan diestimasi.

Model 2: Model efek tetap, dengan efek individu

Pendapatan $=b_{1}$ IDP $+b_{2}$ Pertambangan $+b_{3}$ Kemiskinan $+b_{4}$ Penduduk $+c_{i}+d t+\varepsilon_{i, t}$

\section{Heteroscedasticity Robust Covariance Estimator}

Model 2:

Pendapatan $=b_{1}$ IDP $+b_{2}$ Pertambangan $+b_{3}$ Kemiskinan $+b_{4}$ Penduduk $+c_{i}+d t+\varepsilon_{i, t}$

Test of coefficients:

Estimate Std. Error t value $\operatorname{Pr}(>|t|)$

IDP $\quad 2.68575 \quad 0.880693 .04960 .0038316 * *$

Kemiskinan $20.15842 \quad 4.78441 \quad 4.21340 .0001193 * * *$

Penduduk $166.63158 \quad 35.59426 \quad 4.6814 \quad 2.636 \mathrm{e}-05 * * *$

Pertambangan $4.68360 \quad 1.272673 .68010 .0006210 * * *$ 
Signif. codes: 0 '***' $0.001^{\prime * *} 0.01^{\prime} *$ ' 0.05 '.' $0.1^{\prime}$ ' 1

Dalam model ini tidak terdapat heteroskedatisitas karena semua variabel independen menunjukkan $p$-value lebih kecil dari tingkat siginfikan $\alpha=0.05$.

\section{Analisis Data Random Effect}

Tabel 3. Uji Hausmann

\begin{tabular}{|l|l|l|l|}
\hline Model 3 & 7.3089 & 0.06268 & $\begin{array}{l}\text { Hipotesis } \mathrm{H}_{0} \\
\text { diterima, digunakan } \\
\text { efek random }\end{array}$ \\
\hline
\end{tabular}

Sumber: Data diolah peneliti, 2017

Tabel 4. Uji Breusch-Pagan

\begin{tabular}{|l|l|l|l|l|}
\hline Model 3 & $\mathrm{H}_{0}: \mathrm{c}_{\mathrm{i}}=0, \mathrm{~d}_{\mathrm{t}}=0$ & 34.5345 & $\begin{array}{l}3.169 \mathrm{e}- \\
08\end{array}$ & $\begin{array}{l}\mathrm{H}_{0} \\
\text { ditolak, } \\
\text { ada efek } \\
\text { dua } \\
\text { arah. }\end{array}$ \\
\cline { 2 - 5 } & $\mathrm{H0}: \mathrm{c}_{\mathrm{i}}=0$ & 34.3543 & $\begin{array}{l}4.594 \mathrm{e}- \\
09\end{array}$ & $\begin{array}{l}\mathrm{H}_{0} \\
\text { ditolak, } \\
\text { ada efek } \\
\text { individu }\end{array}$ \\
\cline { 2 - 5 } & Ho: $\mathrm{d}_{\mathrm{t}}=0$ & 0.1803 & 0.6711 & $\begin{array}{l}\mathrm{H}_{0} \\
\text { diterima, } \\
\text { tidak } \\
\text { ada efek } \\
\text { waktu. }\end{array}$ \\
\hline
\end{tabular}

Sumber: Data diolah peneliti, 2017

Dari hasil uji Hausmann dan Breusch-Pagan di atas, dapat disimpulkan bahwa model-model berikut akan diestimasi.

Model efek random, dengan efek individual

Pendapatan $=b_{1}$ IDP $+b_{2}$ Jasa $+b_{5}$ PPKP $+c_{i}+d t+\varepsilon_{i, t}$

\section{Estimasi Model}

Berdasarkan hasil uji Hausman dan Breusch-Pagan menjelaskan hanya terdapat pada model 3 yang sesuai dengan tujuan dari penelitian ini. Model 3 mempunyai efek random dengan efek tetap dimana variabel independennya adalah IDP, Jasa dan PPKP.

Berdasarkan hasil analisis data untuk model 3, diperoleh hasil pengujian berikut.

Effects: var std.dev share

idiosyncratic 5.582e+12 2.363e+06 0.365

individual $9.723 \mathrm{e}+123.118 \mathrm{e}+060.635$

theta: 0.7412

Residuals :

Min. 1st Qu. Median 3rd Qu. Max. 


\section{Coefficients :}

Estimate Std. Error t-value $\operatorname{Pr}(>|\mathrm{t}|)$

(Intercept) 4.3257e+06 1.5766e+06 $2.7437 \quad 0.008317 * *$

IDP $\quad 5.4171 \mathrm{e}+008.8567 \mathrm{e}-01 \quad 6.1164 \quad 1.260 \mathrm{e}-07 * * *$

Jasa $\quad 1.0989 \mathrm{e}+01 \quad 1.9802 \mathrm{e}+00 \quad 5.5495 \quad 9.810 \mathrm{e}-07 * * *$

PPKP $\quad 6.3713 \mathrm{e}+001.3337 \mathrm{e}+00 \quad 4.7771 \quad 1.494 \mathrm{e}-05 * * *$

Signif. codes: 0 '***' $0.001^{\prime} * *$ ' 0.01 '*' $0.05^{\prime}$ '.' $0.1^{\prime}$ ' ' 1

Total Sum of Squares: $1.3871 \mathrm{e}+15$

Residual Sum of Squares: 3.1726e+14

F-statistic: 58.4491 on 3 and 52 DF, p-value: $<2.22 \mathrm{e}-16$

Hasil dari perhitungan estimasi ini dapat disimpulkan bahwa semua independen berpengaruh terhadap variabel dependen. Variabel IDP, Jasa, PPKP p-value lebih kecil dari tingkat signifikan $\alpha=0.05$.

\section{Uji Diagnostik}

Tabel 5. Uji Korelasi Serial

\begin{tabular}{|l|l|l|}
\hline Model & $p$-value & Kesimpulan \\
\hline Model 3 & 0.01392 & $\begin{array}{l}\mathrm{H}_{0} \text { ditolak, } \\
\text { terdapat } \\
\end{array}$ \\
& & $\begin{array}{l}\text { korelasi } \\
\text { serial }\end{array}$ \\
& & 2017 \\
\hline
\end{tabular}

Hasil perhitungan statistik diatas menunjukkan terdapat korelasi serial pada komponen galat. Model 3 tersebut menunjukkan $p$-value yang lebih besar dari tingkat signifikansi $\alpha=0.05$.

\section{Pemilihan Model Terbaik}

Studi kasus ini bertujuan untuk melihat tingkat pengaruh pendapatan per kapita terhadap variabel-variabel fixed effect terdiri dari PDRB Migas dan random effect terdiri dari PDRB Non Migas. Perbandingan setiap model diambil dari setiap hasil estimasi model yang terbaik. Penjelasan variabel-variabel apa saja yang berpengaruh terhadap pendapatan per kapita di provinsi Bangka Belitung akan dijelaskan pada tabel di bawah ini.

Tabel 6. Hasil Perbandingan Fixed Effect dan Random Effect

\begin{tabular}{|l|l|l|l|}
\hline $\begin{array}{l}\text { Nama Variabel } \\
\text { dilihat dari PDRB } \\
\text { Migas dan Non } \\
\text { Migas }\end{array}$ & Model & $\begin{array}{l}\text { Total Sum of } \\
\text { Squares }\end{array}$ & $\begin{array}{l}\text { Residual Sum of } \\
\text { Squares }\end{array}$ \\
\hline Idp, Pertambangan & Fixed effect & $1.2352 \mathrm{e}+15$ & $9.2734 \mathrm{e}+13$ \\
\hline Idp, Jasa, PPKP & Random effect & $1.3871 \mathrm{e}+15$ & $3.1726 \mathrm{e}+14$ \\
\hline
\end{tabular}

Sumber: Data diolah peneliti, 2017 
Melihat hasil tabel di atas model random effect memiliki variabel yang paling banyak berpengaruh terhadap pendapatan per kapita atau pertumbuhan ekonomi di provinsi Bangka Belitung yaitu Industri pengolahan, Jasa-jasa dan Pertanian Peternakan Kehutanan Perikanan, sedangkan model fixed effect hanya dipengaruhi oleh Industri pengolahan dan Pertambangan. Dengan demikian PDRB Non Migas seharusnya lebih diperhatikan dan ditingkatkan hasilnya secara maksimal sehingga dapat meningkatkan kesejahteraan masyarakat Bangka Belitung.

\section{Kesimpulan dan Saran}

\section{Kesimpulan}

Dari pembahasan penelitian ini dapat dsimpulkan bahwa metode Least Square Dummy Variable (LSDV) dapat digunakan untuk menaksir parameter pada model regresi data panel tidak lengkap fixed effect satu arah. Untuk menghasilkan model terbaik dengan data PDRB Migas. Variabel yang tidak terjadi heteroskedastisitas dan model yang memenuhi sum square of error yang terkecil adalah variabel Pertambangan dan Industri Pengolahan, variabel ini berpengaruh terhadapat pendapatan per kapita. Oleh karena itu melihat model di atas dapat dsimpulkan PDRB Non Migas memiliki tiga faktor yang mempengaruhi pendapatan per kapita di Bangka Belitung. Hal ini seharusnya menjadi acuan pemerintah daerah untuk lebih meningkatkan kualitas atau produksi dibidang pertanian dan jasa-jasa karena potensi ini lebih menjanjikan untuk masa yang akan datang.

\section{Saran}

Beberapa saran yang bermanfaat untuk menindaklanjuti penelitian ini adalah perlunya dipelajari metode lain dalam penaksiran parameter pada model regresi untuk data panel tidak lengkap, antara lain metode penaksiran yang menggunakan efek dua arah, Maximum Likelihood dan Restricted Maximum Likelihood.

\section{Referensi}

Baltagi. H. (2005). Econometric Analysis of Panel Data. $3^{\text {rd }}$ ed. John Wiley \& Sons Ltd, Chichester.

Baltagi. H., Seuck H.Song. (2006). Unbalanced Panel Data : A Survey, Statistical Paper 47, 493-523.

BPS.Bangka Belitung.(2015). Data Pertumbuhan Ekonomi di Bangka Belitung 2006-2013

Gujarati. D.(1978), Ekonometrika Dasar (terj.Dra.Ak.Sumarno Zain, MBA). Jakarta : Erlangga

Greene. W. (2003). Econometic Analysis. $5^{\text {th }}$ ed. Prentice Hall, New Jersey.

Irmaningtiyas. Widya.(2014). Estimasi Parameter Model Data Panel Dinamik dengan Kovariat Menggunakan Metode Arellano-Bonal, Tesis, FMIPA, Yogyakarta

Malau, A. (2008). Heteroskedastisitas Dalam Model Panel Fixed Effect Untuk Komponen Galat Cross-Section, Skripsi, FMIPA, Yogyakarta 
IJBE: Integrated Journal of Business and Economics e-ISSN: 2549-3280

Prishardoyo. Bambang.(2008), Analisis Tingkat Pertumbuhan Ekonomi dan Potensi Ekonomi

Terhadap Produk Domestik Regional Bruto (PDRB) Kabupaten Pati (2000-2005), Jurnal Ekonomi, FE, Semarang

Rosadi. D. (2012). Diktat Kuliah Analisis Data Panel. Jurusan Matematika, FMIPA UGM. 